\title{
Gastronomia e Turismo Cultural: um Exercício para a Divulgação de Atrativos Turísticos Brasileiros
}

\author{
Gastronomía y Turismo: un Ejercicio para la Divulgación de Atractivos \\ Turisticos Brasileños
}

\author{
Aliner da Maia Alves ${ }^{1}$; Taiane Motta Rodrigues²; Dra. Mônica Elisa Dias Pons ${ }^{3}$ \\ 1 aliner_ms_alves@hotmail.com, Universidade Federal de Santa Maria; \\ 2taianemotta.rodrigues@gmail.com, Universidade Federal de Santa Maria; ${ }^{3}$ \\ monica@ufsm.br, Universidade Federal de Santa Maria
}

\begin{abstract}
Resumo
O presente trabalho integrou a "Feira Cultural Sabores e Saberes do Brasil", desenvolvida na disciplina de Eventos no Turismo do Curso de Tecnologia em Gestão do Turismo da Universidade Federal de Santa Maria, que tinha como objetivo envolver os alunos em todas as etapas da execução de um evento de divulgação turística. Para o evento foram preparadas bancas pelos alunos, nas quais haviam roteiros de cada região e material visual com os atrativos regionais, tais como: sítios históricos, museus, casas de cultura, festas e celebrações locais, gastronomia típica, artesanato e produtos típicos, feiras e mercados tradicionais, saberes e fazeres locais. Como resultado desta atividade a turma pode compreender melhor as fases da preparação de eventos de divulgação turística, a necessidade de uma boa preparação dos roteiros e material de apoio de atrativos da culinária típica e, principalmente, a motivação desses eventos é o contato direto com o público-alvo que pode gerar um retorno fundamental para um bom planejamento da atividade turística.
\end{abstract}

Palavras-chave: Turismo Cultural, Gastronomia Típica. Organização de EventO, Divulgação Turística.

\section{Introdução}

Cada vez mais o turismo é reconhecido como de importância para o mundo contemporâneo. No dizer de Pinheiro,

O turismo é um elemento importante da vida social e econômica da comunidade, seja ela Municipal, Regional ou Nacional. A função do turismo é a captação de divisas para os países, a atividade é considerada uma das mais expressivas na economia mundial. Considerada a maior prestadora de serviços no mundo, é um grande gerador de empregos, de renda e de divisas, podendo vir a ser a solução para o desenvolvimento econômico-social de uma nação (PINHEIRO, 2008, p.2).

Segundo Dias e Cassar (2005), o turismo é um conjunto de atividades realizadas pelos turistas em viagens com duração menor que um ano, onde as pessoas estão em locais diferentes da sua residência, com o objetivo de lazer, negócios, saúde, aventura, entre outros motivos, mas que não sejam utilizadas como fins lucrativos. Já o turismo cultural apresenta um aspecto duplo: um destes é como um caminho para a obtenção de fundos necessários para a preservação da herança cultural e o outro como uma ferramenta para proporcionar o desenvolvimento econômico local, regional e/ou nacional (DIAS, 2006). 


\section{Revisão Bibliográfica}

Esta breve revisão bibliográfica contém as principais discussões da base teórica utilizada para o desenvolvimento do tema proposto. Está dividida nos temas: turismo, turismo cultural, gastronomia e turismo, turismo gastronômico e eventos.

Andrade (2008), diz que Turismo é um conjunto de atividades e serviços, tendo como objetivo o planejamento, a promoção e a execução de viagens, e também serviços, como hospedagem, recepção, transporte e atendimento aos turistas, que estejam fora de suas residências habituais. Encontra-se, nos Marcos Conceituais do Ministério do Turismo do Brasil (2006, p.12), a definição de Turismo Cultural como sendo "as atividades turísticas relacionadas à vivência do conjunto de elementos significativos do patrimônio histórico e cultural e dos eventos culturais, valorizando e promovendo os bens materiais e imateriais da cultura". Sendo assim, o turismo cultural é um dos setores de atração turística que mais gera oportunidades de desenvolvimento social e econômico local e regional.

Da mesma forma,

Gastronomia e o Turismo são indissociáveis, pois é impossível pensar em turismo sem prever a alimentação para curta ou longa permanência. Os lugares possuem seus pratos típicos e seu modo peculiar de preparar e apresentar os alimentos, tornandoos características culturais e símbolos de identidade (BARCZSZ e AMARAL, 2010, p.70)

Em qualquer destino, o viajante precisa da alimentação e assim acaba experimentando a cozinha da localidade. Por sempre andarem juntos desde o início da alimentação, os apreciadores da boa comida viajam para comer e conhecer algo diferente (CORNER, 2004). Já o turismo gastronômico é aquele em que o turista tem como objetivo principal de sua viagem experimentar/experienciar os prazeres de uma culinária diferente e única, está associado às sensações do gosto e do paladar. Desta forma, muitas cidades e regiões turísticas investem na organização de roteiros gastronômicos para captar esse público, que deseja conhecer a cultura, a história e as tradições através da culinária local e regional. O turismo gastronômico torna-se dia a dia uma realidade, é um dos setores da atividade turística que mais amplia postos de trabalho no setor da alimentação (restaurantes, bares, lanchonetes e ambulantes), da agroindústria e da agricultura familiar, proporcionando melhorias na economia local e para a população regional (CORNER, 2006).

Sabemos que é necessário que o profissional em Gestão do Turismo esteja capacitado para desenvolver roteiros culturais adaptados a diversos gostos e necessidades, tanto do turista nacional quanto do estrangeiro. Dessa forma, a atividade prática é a oportunidade dos discentes vivenciarem todas as etapas do fazer profissional, tais como, análise das potencialidades regionais, levantamento da infraestrutura receptiva, meios de transporte e hospedagem, elaboração de roteiros turísticos, divulgação em eventos e feiras.

A dimensão e a diversidade do território brasileiro são de tal ordem que a estruturação e organização da oferta turística do País constituem um dos maiores desafios para a gestão e o desenvolvimento sustentável da atividade. A estruturação da oferta turística pode ser potencializada, se considerada em sua dimensão regional, em que diversos municípios se integram e se complementam na prestação de serviços aos turistas, agregando valor aos territórios (BRASIL. MINISTÉRIO DO TURISMO, 2013, p. 6). 


\subsection{Eventos}

Já um evento é, conforme Britto e Fontes,

uma ação profissional que envolve pesquisa, planejamento, organização, coordenação, controle e implantação de um projeto, visando atingir o seu públicoalvo com medidas concretas e resultados projetados (BRITTO E FONTES 2004, p. $20)$.

Pode-se fazer uma analogia entre as principais características da atividade turística com as atividades de organização de um evento. Elas englobam um grupo de serviços, uma cadeia de produção, uma organização logística, a alocação e gerenciamento de recursos humanos e a produção de valores simbólicos e materiais. A meta maior da gestão destas atividades é que ocorra sincronia entre os agentes envolvidos numa perfeita integração dos processos de gestão (BARBOSA, 2013, 92).

Por fim, Bahl refere que turismo de eventos é um

acontecimento que ocorre a partir de um motivo e de atividades programadas a serem desenvolvidas em um local e tempo determinados, congregando indivíduos com interesses e objetivos comuns, de mobilização da cadeia produtiva e serviços públicos de uma localidade (BAHL, 2004, p.18).

\section{Metodologia}

Para o trabalho de preparação do evento, a turma foi dividida em grupos para a execução das tarefas, entre elas estavam pesquisa em mídias e a revisão bibliográfica especializada para a elaboração de três roteiros turísticos para cada uma das regiões brasileiras, sempre com a temática do turismo cultural e da gastronomia típica. Para o evento foram selecionadas receitas das gastronomias típicas regionais para execução e distribuição aos visitantes. Além de preparação de bancas com alunos explicando os roteiros de cada região e material visual com os atrativos regionais, tais como: sítios históricos, museus, casas de cultura, festas e celebrações locais, gastronomia típica, artesanato e produtos típicos, feiras e mercados tradicionais, saberes e fazeres locais.

\section{Considerações finais}

Como resultado desta atividade a turma pode compreender melhor as fases da preparação de eventos de divulgação turística, a necessidade de uma boa preparação dos roteiros e do material de apoio (cartazes, folhetos, etc.), de atrativos relacionados a culinária típica e, principalmente, a motivação desses eventos é o contato direto com o público-alvo que pode gerar um retorno (feedback) fundamental para um bom planejamento da atividade turística. Por fim, cabe ressaltar, que mesmo que o evento tenha tido a participação de um público universitário (e bem informado) ficou evidente a potencialidade turística das diferentes regiões brasileiras.

Também foi possível perceber que a organização de um evento envolve muitas etapas e serviços especializados, somente a compreensão da complexidade destas etapas pode levar ao sucesso de um evento. Como o turismo de eventos tornou-se uma área específica da atividade turística é necessário que tenha-se conhecimento dos conceitos e práticas para a adequada concepção, planejamento e organização de eventos no Turismo.

Por fim, é necessário compreender a gastronomia como um fenômeno cultural complexo que faz parte da construção da identidade de um determinado grupo social. A 
simples reprodução de uma receita ou prato típico não reproduz a riqueza de informações que o turista pode experienciar na visita aos locais de culinária regional.

\section{Referências}

ANDRADE, José Vicente de. Turismo: fundamentos e dimensões. $8^{\mathrm{a}}$ edição. São Paulo: Ática, 2008.

BAHL, M. Turismo e Eventos. Curitiba: Protexto, 2004.

BARBOSA, Fabrício Silva. Planejamento estratégico para eventos: um estudo de caso das estratégias de marketing utilizadas pela Oktoberfest de Santa Cruz Do Sul/RS. CULTUR Revista de Cultura e Turismo, Ano 07, nº 01, Fev. 2013, p.87-104.

BARCZSZ, S.D; AMARAL, F.F. Turismo gastronômico: a percepção do turista na $18^{\mathrm{a}}$ festa nacional do carneiro no buraco de campo mourão estado do Paraná. Patrimônio: Lazer \& Turismo, v.7, $\mathrm{n}^{\mathrm{o}} 11$ jul.-ago.-set./ 2010, p.66-98. Disponível em

http://www.unisantos.br/pos/revistapatrimonio/pdf/Artigo4_v7_n11_jul_ago_set2010_Patrim onio_UniSantos_(PLT_33).pdf. Acesso em 06/05/2014.

BRASIL. Ministério do Turismo. Marcos conceituais do Ministério do Turismo, 2006.

Disponível em

htpp://www.turismo.gov.br/sites/default/turismo/o_ministerio/publicacoes/downloads_publica coes/Marcos_Conceituais.pdf, acesso em 18/05/2015.

BRASIL. Ministério do Turismo. Programa de Regionalização do Turismo: Diretrizes.

Ministério do Turismo/ Secretaria Nacional de Políticas de Turismo: Brasília, 2013.

BRITO, Janaína; FONTES, Nena. Estratégias para eventos: uma ótica do marketing e do turismo. São Paulo: Aleph, 2002.

CORNER, Dolores Martin Rodriguez. A Gastronomia como Atrativo no Turismo Cultural. Anais do IV Seminário de pesquisa em Turismo do Mercosul. Caxias do Sul, 7 e 8 Jun. 2006. Disponível em:

http://www.ucs.br/ucs/tplSemMenus/posgraduacao/strictosensu/turismo/seminarios/seminario _4/arquivos_4_seminario/GT03-6.pdf, acesso em 18/05/2015.

DIAS, Reinaldo. Turismo e Patrimônio Cultural: recursos que acompanham o crescimento das cidades. São Paulo: Saraiva, 2006.

DIAS, Reinaldo; CASSAR, Maurício. Fundamentos do Marketing Turístico. São Paulo: Prentice Hall, 2005.

PINHEIRO, Andréa Freitas. Uma Análise dos Fatores Favoráveis à Prática do Turismo de Aventura no Município de Quixadá - CE. Anais do II Seminário Internacional de Turismo Sustentável, Fortaleza-CE, 2008.

SANTOS, N. R. Z. dos; CERETTA, C. C.; ZIEMANN, D. R. Cafés coloniais como referência cultural e atrativo turístico no município de Agudo, RS, Brasil. Geografia Ensino \& Pesquisa, v. 19, n.1, p. 39-48, jan./abr. 2015. 